Globus An International Journal of Management \& IT

A Refereed Research Journal

Vol 11 / No 1 / Jul-Dec 2019 ISSN: 0975-721X

\title{
A STUDY ON TAXONOMY OF INNOVATIONS
}

\author{
*Nidhi Agarwal \\ **Monika Verma
}

\begin{abstract}
The reflective mirrors in design path one and design path two enabled the exponential increase of the power of the instructional strategies through application of identified learners' needs and insertion of characteristics of successful innovations. These innovative instructional strategy is creative oriented which is able to solve the problem of the learners. In today's scenario, the most suitable strategy are those which make teaching joyful \& learning a passion to excel, go beyond it, be human, respect others \& be a professional, at all times. Without innovation, our education system will never attain first world status. So, in this knowledge economy it is necessary to innovate pedagogies to enrich the classroom experience \& to make it memorable \& enjoyable. Latest ICT make this quite easy. In this regard, TCSEducation World encourage \& inspire teachers to innovate new practices \& pedagogies, to make learning joy full \& improve learning outcomes through innovative strategies like field trips, outdoor activities for experiment learning or learning by discovery. The present article describes that how these new innovations play a significant role in instructional strategies. These latest innovations are now making possible for teacher to dynamically interact \& collaborate with subject content. Because it makes them more than one sense simultaneously. This article assesses the effectiveness of instructional delivery teacher training \& education programme. Professional development of teacher is depending upon these new emerging innovative ideas. It enhances the efficacy of transaction \& productivity. The main purpose is to determine the use of innovative strategies \& method of teaching including the latest technological gadgets.
\end{abstract}

Keywords: Augmenting, Collaboration, Strategies, Lucrative, Exponentially, Simulated, Pedagogies.

\section{Introduction}

\author{
"Tell me and I forget. Show me and I \\ remember; Involve me and I understand". \\ Chinese Proverb
}

Education is the most important factor to progress the country. It is important not only for the full development of one's personality, but also for the sustainedgrowth of the nation. Basicallyy, Indian education systemcompound of three components and they are primary education, secondry education and higher education. The educational structure in India is generally referred to to as $10+2+3$ pattern.Here, we are onlyconcern with +3 stage/level which involves college education and above level, the student goes for higher and reseach in his chosen field of the subject. Indians cliams to have the second largest higher education system in the The educational structure in India which operates at all conceiable levels from pre-school to postdoctoral of monumental proportions.

*Principal, Integrated School of Education, Ghaziabad, UP. E-mail: nidhiagarwal0607@ gmail.com

**Teacher, Kingdom of Bahrain. 


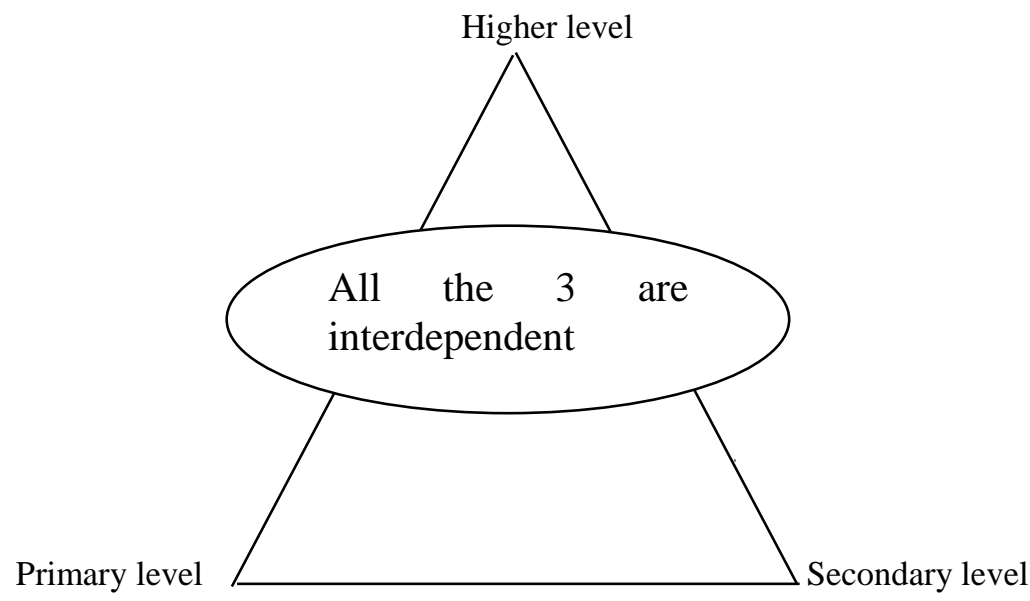

Figure 1: Three Pillars of Indian Education System

\section{Taxonomy of Innovation}

The eight types of innovations include "replication, redefinition, forward incrementation, advance forward incrimination, redirection, reconstruction, re-initiation and integration". Teacher education innovations presented in this issue reflect this taxonomy. For example, innovation through integration can be seen in this issue in Teemant's application of socio-cultural theory to a bilingual distance education program. The innovation of reconstruction is highlighted in this issue by Whittaker, McDonald, and Markowitz, who reconstruct multicultural pedagogy to create new ways of providing instruction. In this issue the innovation of advance forward incrementation is evidenced in Sindelar, Bishop, Brownell, Rosenberg, and Connelly wherein special education teacher preparation is examined and projected in successive studies to provide viable and defensible avenues for future research.

In contrast, Robertson (1971) suggests three types of innovation: continuous innovation, dynamic innovation, and discontinuous. Continuous innovation in teacher education would include program revisions based on student outcomes assessment as recommended in this issue by Hall, Nowinski, and Smith and by Sindelar, Bishop, Brownell, Rosenberg, and Connelly and as practiced by Wong and Glass as well as Karayan and Gathercoal. Dynamic innovation is exemplified by data-based triangulation of assessments gathered from students, instructors, and field-based constituents for the purpose of program development and/or modification such as the research reported in this issue by Donnell and Harper as well as Wong and Glass. Finally, discontinuous innovation supports individual faculty efforts, perhaps through program improvement grants to produce innovation for a specific area, such as the study in this issue by McClintock, O'Brien, and Jiang in mathematics education. Moreover, the taxonomy of innovations in teacher education featured in this issue include collaborative partnerships (Sindelar et al.; Teemant; Wong \& Glass; McClintock et al); professional development schools (Wong \& Glass); integration of technology (Karayan \& Gathercoal; Teemant); standards-based teacher education (Hall, Nowinski, \& Smith); data-based professional development (Teemant; Wong \& Glass; Whittaker et al.); alternative certification (Sindelar et al); graduate follow-up programs (Whittaker et al); teacher recruitment and induction (Wong \& Glass). In addition, the topic of teacher education reform and accountability is addressed by all authors.

\section{The Innovation Candle Lights}

"For a prosperous \& developed India, the important thrust will be on the growth in the number of Invisible leaders \& Innovative Organizations"

\section{Hon'ble Late Dr APJ Abdul Kalam (Former President of India) Indian Innovation Awards 2005 Ceremony held at Vigyan Bhawan on March 7, 2005}

"There is need for greater awareness amongst the people concerning some of this conceptual ideas-to haqve innovation as a national movement, just as pandit Jawaher Lal Nehru had always talked of the nation and society being imbued with the scietific 
temper that characterizes a scientific approach to the very functioning of life."

MGK Menon, Chairman, Jury Initiatives; A Spot Bulletin of EMPI Institute, Vol, I, 2005

"NIF (National Innovation Foundation of India) has been set up to give expression to the $94 \%$ population which has been neglected so far. They comprise of artisans, tribals farmers, the unemployed, the illetrate $\&$ the youth. In order to survive \& succeed they keep on innovating. The challenge is to connect the $6 \%$ that is exposed to modern science and technology in a formal waqy with $94 \%$."

RA Mashelkar, Chairman of NIF, Interview Business world, 21(36), 30, 2002

Table 1: Attributes of Innovations and Their Effects on Individual's Perception of Innovations

\begin{tabular}{|c|c|c|}
\hline Attributes & Definition of Attribute & Individual's Perception of Attribute \\
\hline $\begin{array}{l}\text { Relative } \\
\text { Advantage }\end{array}$ & $\begin{array}{l}\text { The degree to which an innovation is } \\
\text { perceived as better than the idea it } \\
\text { supercedes. }\end{array}$ & $\begin{array}{l}\text { The relative advantage of an innovation, } \\
\text { as perceived by members of a social } \\
\text { system, is positively related to adoption. }\end{array}$ \\
\hline Compatibility & $\begin{array}{l}\text { The degree to which an innovation is } \\
\text { perceived as consistent with existing } \\
\text { values, past experiences, and needs of } \\
\text { potential adopters. }\end{array}$ & $\begin{array}{l}\text { The compatibility of an innovation, as } \\
\text { perceived by members of a social } \\
\text { system, is positively related to adoption. }\end{array}$ \\
\hline Complexity & $\begin{array}{l}\text { The degree to which an innovation is } \\
\text { perceived as relatively difficult to } \\
\text { understand and to use. }\end{array}$ & $\begin{array}{l}\text { The complexity of an innovation, as } \\
\text { perceived by members of a social } \\
\text { system, is negatively related to adoption. }\end{array}$ \\
\hline Trialability & $\begin{array}{l}\text { The degree to which an innovation may } \\
\text { be experimented with on a limited basis. }\end{array}$ & $\begin{array}{l}\text { The trialability of an innovation, as } \\
\text { perceived by members of a social } \\
\text { system, is positively related to adoption. }\end{array}$ \\
\hline Observability & $\begin{array}{l}\text { The degree to which the results of an } \\
\text { innovation are visible to others. }\end{array}$ & $\begin{array}{l}\text { The observability of an innovation, as } \\
\text { perceived by members of a social } \\
\text { system, is positively related to adoption. }\end{array}$ \\
\hline
\end{tabular}

Figure 2: Diffusion of Innovations

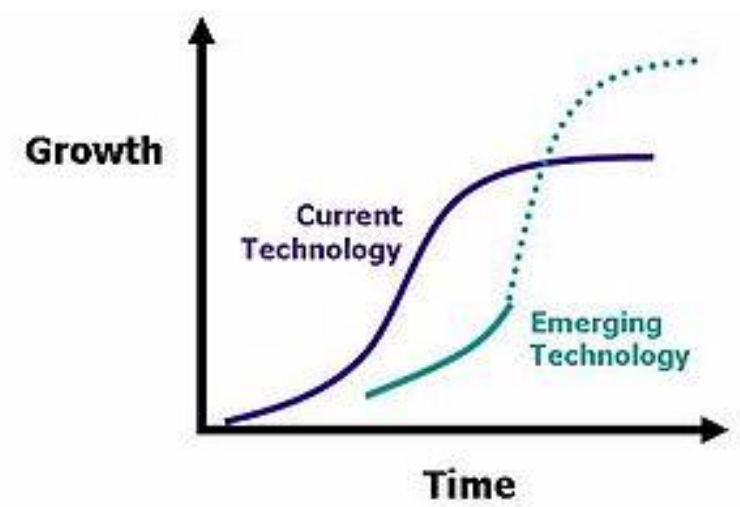

Once innovation occurs, innovations may be spread from the innovator to other individuals and groups. This process has been proposed that the life cycle of innovations can be described using 's-curve'. The s-curve maps growth of revenue or productivity against time. In the early stage of a particular innovation, growth is relatively slow as the new strategy establishes itself. At some point users begin to demand and prescribes growth increases more rapidly. New incremental 
innovations or changes to the product allow growth to continue. Towards the end of its life cycle growth slows and may even begin to decline. In the later stages, no amount of new ideas in that strategy will yield a normal rate of return.

The s-curve is derived from half of a normal distribution curve. There is an assumption that new ideas are likely to have "product Life"; i.e. a startup phase, a rapid increase in results and eventual decline. In fact the great majority of innovations never get off the bottom of the curve, and never produce normal returns.

Innovative person will typically be working on new innovations that will eventually replace older ones. Successive s-curves will come along to replace older ones and continue to drive growth upwards. In the figure above the first curve shows a current technology. The second shows an emerging technology that current yields lower growth but will eventually overtake current technology and lead to even greater levels of growth. The length of life will depend on many factors.

There are various innovative instructional strategies, which is effectively using in higher education to improve and maintain the teachinglearning quality. These are as follows:

- Cooperative Learning (CL) - This method mostly aims at the development of cognition, which includes thinking, remembering, concept formation, problem solving \& logical reasoning. It provides opportunities for a teacher to interact with others learners in the class. They enable all the learners to work together \& arrive at the final solution on the basis of teamwork. It promotes participation of all learners. It not only contributes to intellectual development but also equally contribute to social \& psychological development of the learner unlike other method of instruction. Moreover, it is an act of practicing face-to-face interaction learning so to encourage creativity \& foster critical thinking through group discussion (GD). Research clearly indicated that cooperation learning compared with competitive \& individualistic efforts typically results in team spirit, interpersonal relationship, self-esteem, motivation \& leadership quality etc. Some well known methods of cooperative learning (CL) are Group Investigation (GI), Learning Together (LT), Reciprocal Teaching of Reading (RTR), Cooperative Integrated Reading \& Composition (CIRC), Jigsaw I \& II, constructive controversy (CC) / structured academic controversy (SAC), student Teams - Achievement Divisions (STAD) \& Teams - Games Tournament (TGT). Thus, it helps the teacher in achieving thousands of goals of education because they incorporate intellectual, social \& psychological aspects of education \& develop interpersonal relationship among learners.

- Blended Learning- A blend is an integrated method for delivering on promises about learning \& performance. It means a mash up of different training delivery methods-ILT, word documents, PDFs, pod casts, movies, online course, tests etc. Blending involves a planned combination of approaches, such as coaching wise supervisor; participation in an online class; breakfast with colleagues; competency descriptions; reading on the beach; reference to a manual; collegial relationships; and participation in seminars, workshops, and online communities. Moreover, it is the process of incorporating different types of learning style to accomplish the learning process through the use of virtual and physical resources. Learning styles refers to the different ways in which people learn. Through blended learning, this can be accomplished by creating a variety of learning assignments and activities withy the use of technology and instructor/peer interaction. Technology (Internet \& software application) is the key driver towards the development of existing state of blended learning, which used to be ILT (Instructor Led Training) earlier. Blended learning is a hot and understandably so, combining the best features of online learning (e.g.24X7 accessibility) with the best features of classroom instruction (e.g. live, face-to-face interaction). No doubt it's here to stay. Options for blended learning go beyond the classroom. They're formal and informal, technologyand people- based, independent and convivial, and directive- and discoveryoriented. It becomes all the more effective when people (learners, teachers, administrators) from more than two countries are involved. They get a chance to interact with each other know and experience each other's cultures. If such seminars, conferences are organized that 
give people from different countries to interact the benefit is not only in terms of knowledge gain but also in terms of having a feel of each other's culture. Like participants of the conference would have gained something they would not have had they been only relying on Internet or e- learning, which leads to improved participants interaction and satisfaction.

The table 2 below presents the possibilities of what can constitute a blended learning approach:

\begin{tabular}{|c|c|}
\hline $\begin{array}{l}\text { Live face-to-face (formal) } \\
\text { - Instructor - led classroom } \\
\text { - } \quad \text { Workshops } \\
\text { - } \quad \text { Coaching/mentoring } \\
\text { - } \quad \text { On- the job (OTJ) training }\end{array}$ & $\begin{array}{l}\text { Live face-to-face (informal) } \\
\text { - Collegial connections } \\
\text { - } \quad \text { Work teams } \\
\text { - } \quad \text { Role modeling }\end{array}$ \\
\hline $\begin{array}{l}\text { Virtual collaboration/synchronous } \\
\text { - Live e-learning classes } \\
\text { - E-learning }\end{array}$ & $\begin{array}{l}\text { Virtual collaboration/synchronous } \\
\text { - Online bulletin boards } \\
\text { - Online communities }\end{array}$ \\
\hline $\begin{array}{l}\text { Self-paced learning } \\
\text { - } \quad \text { Web learning modules } \\
\text { - } \text { Online resource links } \\
\text { - } \quad \text { Simulations } \\
\text { - } \quad \text { Scenarios } \\
\text { - } \quad \text { Video \& audio CD/DVDs } \\
\text { - } \quad \text { Online self assessments } \\
\text { - } \quad \text { Workbooks }\end{array}$ & $\begin{array}{l}\text { Performance support } \\
\text { - } \text { Help systems } \\
\text { - } \text { Print job aids } \\
\text { - } \quad \text { Knowledge database } \\
\text { - } \quad \text { Documentation } \\
\text { - } \quad \text { Performance/decision supports tools }\end{array}$ \\
\hline
\end{tabular}

Source: Strategies For Building Blended Learning By Allison Rossett, Felicia Douglis, and Rebecca V. Frazee

As stated before, one obvious advantage of blended learning is its ability to maximize effectiveness by matching the best medium for each learning object.

- Project Based Learning- "Project based learning" is an authentic instructional modal or strategy in which learner plan, implement, and evaluate projects that have real world application beyond the classroom (Blank, 1997; Dickinson, et al, 1998; Harwell, 1997). Learning activity that are interdisciplinary, long term, and student centered are emphasized, rather than short, isolated lessons (Challenge 2000; Multimedia Project, 1999). Project based instructional strategies have their roots in the constructivist approach evolved from the work of psychologist and educators such as Lev Vygotsky, Jerome Bruner, Jean Piaget and John Dewey. Constructivism views learning as the result of mental construction; that is, students learn by constructing news 
ideas or concepts based on their current and previous knowledge (Karlin \& Vianni, 2001). Most important, students find projects a fun, motivating, and challenging because they play an active role in choosing the project and in the entire planning process (Challenge, 2000; Multimedia Project, 1999; Katz, 1994).

- Case Study- The case study method forces the teacher to grapple the exact kind of decisions \& dilemmas that they confront everyday. This is the effective method of teaching pedagogy. It is the most practical way of providing the student with a variety of problems to apply the knowledge \& skills that they acquire in their studies. It allows the selection of problem $\&$ decision-making scenarios \& the level of complexity in a controlled environment \& in a relatively short span of time. It helps transfer knowledge from the classroom to real practice, develop interpersonal skills, illustrate particular points, develop judgment wisdom, self-analysis, attitudes confidence \& responsibility, enliven teaching \& bring realism into instructional settings. Its strength is-

- Relies on learning by analysis \& discussions.

- $\quad$ Help students in decision making skills

- Participants to learners to present their ideas clearly

- Allow learning of social skills

- Simulated Teaching- It is recent innovation in teacher education program, which aim at modifying teacher's behavior according to specified objectives. This practice makes training a continuous process with scope for daily improvement and to develop confidence and required competencies in student teachers, not limiting it to teaching practice only.

- Peer Learning- The high achievers acted as peer-tutors, who extended academic support under the guidance of the concern teacher. Co-operative learning strategy, peer tutoring and self-learning materials can be immense use for the teachers for handling heterogeneous group of learners. This pragmatic strategy may be applied at secondary and higher level. The must know this strategy so that they can eliminate learning gaps among the learners to a large extent.

- Tutorials- The main purpose of tutorials is to develop learner ability to think independently, to search for knowledge on their own and to be able to tackle new problems independently. So, the basic theme of this strategy is that all learners should have minimum knowledge of the concern subject.

- E-Learning- E-Learning technique in teacher education are 3 still at a nascent stage. It is actually web-based teaching with inputs of techniques like animations, visualization, virtual environments, simulations \& games, text audio, video \& lots of activity building teaching programs. This helps the learners to get trained at the3ir own place, based on their own convenient time $\&$ is of course self- paced. Through e learning, they will not only acquire crucial concept of the subject but esimulations \& e-games also give them practical exposure to the teaching-learning process.

- In Circle Time- "In circle Time" pioneered by British educationist Jennes Mosley. Learners have to stand/sit in circle with each one encouraged open up and talk about issues, which promote esteem and positive behavior. It enriches learner's vocabulary communication skills, and boosts their selfconfidence. Moreover, it is a unique strategy that focuses on dialogue and an open exchange of ideas to develop new practices and action plans on-site. The learning circle approach helps enhance your experience and stimulate creativity and innovation.

\section{- $\quad$ Team Teaching}

- Team teaching is another innovative approach in teaching large groups in which, two or more educators share the responsibility for a group of students, an individual teacher no longer has to be all things to all the students.

- It allows the teacher to apply his/her strength, interest, skills \& ability to the greatest effect, knowing that children would not suffer from his/her weakness because there is 
someone with a difference set of abilities to back his/her up.

- Truly professionalize teaching.

- Just as good low firm has mix of associate, and junior partners, school should have a greater mix of teachers who have appropriate levels of responsibility based on their abilities $\&$ experiences level as much of lawyers work occurs outside the courtroom.

\section{Advantages}

- The best teacher in an institution are shared by most students.

- It undertakes the act of teaching by a group of teachers (2or more) rather than by single teacher.

- A team of teachers of the same subject work together to deal a significant content to same group of students jointly.

- Teachers make better use of teaching techniques \& teaching devices. It results in the improved instruction of the teachers \& quality learning of the students.

\section{- Mind Mapping}

Mind maps are a dynamic way to capture significant points of information. It is a technique that ruins your brain to see the whole picture \& details to integrate logic \& imagination. The three A's of mid mapping are Accept, Apply\& Adapt. It is more effective because-

-It helps association easily.

-Very attractive.

- Helpful in summarizing information.

- Enable to increase the retention.

- Improve mental abilities.

A mid map can be drawn using the following steps-

- Begin by putting the central theme in all directions in the middle of the page.
- Work out word from the central theme in all directions in the form of main branches.

- Use symbols, colors, words pictures, images etc. against the branches.

- Use thick lines to represent the main branches \& thinner lines to represent the sub- branches.

- $\quad$ Print the key words per lines. Provide white space between the information.

- Make the mind map bold, memorable \& colorful.

- Practice it before the teaching-learning process.

Instructional strategy helps teachers in planning instruction-selecting and sequencing content matter, selecting appropriate instructional methods and media, providing appropriate learning experiences and selecting appropriate evaluation techniques. In addition, it helps in determining effectiveness of instruction and taking appropriate corrective actions to enhance effectiveness of instruction. It also enables teachers to communicate more effectively what they teach.

\section{Conclusion}

Innovation and effectiveness in instructional strategy and design, a wholistic approach is adopted from a system point of view where the components of the system are interdependent and interrelated. Change in any component cannot be done in isolation because the change made can affect the system either adversely or favorably. Development of instructional strategy and design is a systematic process comprising a series of steps ranging from need analysis to diffusion, ensuring maximum success in implementing such instructional strategy in the actual classroom situation. Because, in the higher education student interaction levels are very high, listening, responding verbally/non-verbally, talking case of individual difference are part of the professionalism exhibited by the teacher. In this context, Intel-Teach programme provided contemporary ICT training which has enabled teacher educators and student teacher to integrate technology into their lessons, and promote problem solving, critical thinking, and collaboration in their classrooms. Above all, now it is essential for teachers learn the art of reinforcement, acknowledging the progress of the learner and praising them, to assure them that they are learning 
and doing well, and as a teacher is accepting that the desired learning is the taking place.

\section{References}

1. King, N., (2003). Involvement in innovation: The role of identity. In L. V. Shavinina (Ed.), The International Handbook on Innovation, London, London, UK: Pergamon, 619-630.

2. Kostoff, R. N., (2003). Stimulating innovation. In L. V. Shavinina (Ed.), The International Handbook on Innovation, London, UK: Pergamon, 388-400.

3. Marinova, D., \& Phillimore, J., (2003). Models of Innovation. In L. V. Shavinina (Ed.), The International Handbook on Innovation, London, UK: Pergamon, 44-53.

4. Ruchika, Gupta and Agarwal, S.P., (2017). "A Comparative Study of Cyber Threats in Emerging Economies". Globus: An International Journal of Management \& IT, 8(2); 24-28, ISSN: 0975-721X

5. Singh, Gurinder, Kumar, Bhawna and Gupta, Ruchika, (2018). "Role of Consumer's Innovativeness \& Perceived Ease of Use to Engender Adoption of Digital Wallets in India". ICACE2018, IEEE Xplore, pp.150-158, (Scopus Indexed).

6. Srivastava, Priyanka, Shukla, Rajendra Kumar, Sharma, Shubham, Khanduja, Dinesh, Gupta, Ruchika and Alrasheedi, Melfi, (2020). "Fuzzy Methodology Approach for Prioritizing Maintenance 4.0 Attributes". ICCAKM 2020, IEEE Xplore (Scopus Indexed).

7. Kumar, Puneet and Gupta, Ruchika, (2008). "Information System's Security by using Matrices and Graphs". Conference proceedings on Information Security and
Mobile Computing, ABES Engg College, 62-66.

8. Agarwal, Nidhi and Shiju, P.S., (2018). "A Study on Content Generation for Internet Usage". International Journal of Advanced Research and Development, 3(2); 13801382; doi: 10.5281/zenodo.3764806.

9. Agarwal, Nidhi and Shiju, P.S., (2018). "A Study on CMS with Web Usage Solutions". International Journal of Advance Research and Development, 3(2); 1683-1685; doi: 10.5281/zenodo.3807435.

10. Agarwal, Nidhi and Pundir, Neelam, (2017). "Information and Communication and Its Importance". Ambikeya Journal of Education, 8; 40-42; ISSN: 0975-9735.

11. Agarwal, Nidhi and Kumar, Puneet, (2009). "Role of Information Technology in Education". AICTE Sponsored National Conference on Information Integrity \& Supply Chain Management Abstracts Proceeding, Book World Publisher, Dehradun, 18.

12. Agarwal, Nidhi, (2009). "Reflection on the Impact of ICT on Teacher Education". Paradigm Shift in Teacher Education, Vayu Education of India, 5, ISBN: 978-93-8009712-1.

13. Goel, Agarwal, Nidhi, (2008). "A Global Change in Education through Information Technology and Communication". Enterprises Information Systems \& Technology, Mac Millan Advanced Research Series, 124-126; ISBN 10: 0230635-16-4; ISBN: 13: 978-0230-63516-6.

14. Kapri, Tapan and Kumar, Puneet, (2011). "Web Content Management System". Information and Communication Technology", Excel India Publishers, New Delhi, 8-10. 